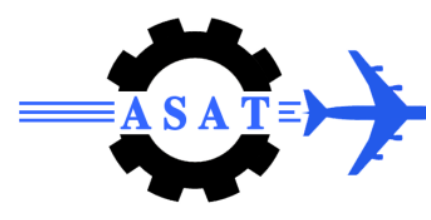

\title{
Aerothermodynamics of Spiked Bodies: Part I
}

\author{
M.Y.M. Ahmed*, N. Qin ${ }^{\dagger}$
}

\begin{abstract}
Among a variety of design requirements, reducing the drag and aeroheating on hypersonic vehicles are the most crucial. Unfortunately, these two objectives are often conflicting. On one hand, sharp slender forebodies design reduces the drag and ensures longer ranges and more economic flights. However, they are more vulnerable to aerodynamic heating. On the other hand, blunt forebodies produce more drag however, they are preferred as far as aeroheating is concerned. In addition, in the context of hypersonic vehicles, blunt geometries are preferred over slender ones for practical implications such as higher volumetric efficiency, better accommodation of crew or on-board equipment.
\end{abstract}

In principle, a blunt vehicle flying at hypersonic speeds generates a strong bow shock wave ahead of its nose which is responsible for the high drag and aeroheating levels. There have been a number of efforts devoted towards reducing both the drag and aeroheating by modifying the flowfield ahead of the vehicle's nose. Of these techniques, using spikes is the simplest and the most reliable technique. A spike is simply a slender rod attached to the stagnation point of the vehicle's nose. The spike replaces the strong bow shock with a system of weaker shocks along with creating a zone of recirculating flow ahead of the forebody thus reducing both drag and aeroheating.

Since their introduction to the high-speed vehicles domain, spikes have been extensively studied using both experimental facilities and numerical simulation techniques. The present review study is devoted to surveying these contributions and illustrating the recent contributions of the authors in this field. The present study also raises some of the areas in the field that need further investigations. For a clearer illustration, the study is presented in two separate papers. The present paper, Part I, is intended to serve as an index for previous literature that could be useful for the interested researchers. The other part of this paper deals with the recent advances of spiked bodies aerothermodynamics and up-to-date contributions.

\section{Introduction}

Among a number of design requirements, the reduction of both drag and aerodynamic heating is the major challenge in the design of supersonic and hypersonic vehicles. Reducing the aerodynamic drag on these vehicles ensures reaching the desired range (or altitude) and, in the same time, enables economizing the fuel usage, simplifying the propulsion system requirements, and maximizing the ratio of payload to take-off gross weight [1]. Pointed bodies generate less drag compared with blunt bodies at supersonic and hypersonic conditions. Hence, they provide a good choice as far as drag reduction is concerned.

\footnotetext{
Egyptian Armed Forces, Egypt.

$\dagger$ Professor of Aerodynamics, Department of Mechanical Engineering, University of Sheffield, Sheffield, UK.
} 
Unfortunately, in the context of high speed vehicles' design, pointed bodies cannot be employed due to the extreme levels of aerodynamic heating associated with these bodies in high speed regimes. High levels of aerodynamic heating can cause malfunction [2] or even damage of the delicate on-board electronic devices [3,4]. In addition, excessive heating can cause ablation to the vehicle material which yields fluctuations in the vehicle performance [5]. In the presence of high pressure loads, severe heating can cause a complete material failure [6] or at least surface erosion [7]. Employing the conventional thermal protection systems (TPS) complicates the design, increases the burn-out weight, or deteriorates the original design, as in the case of ablating shields. Extreme aeroheating levels experienced by re-entry vehicles further complicate the TPS requirements and result in communication black-out due to ionization of air; a problem that cannot be resolved using TPS. Blunt bodies were found to yield lower heating levels compared with their pointed counterparts since they tend to distribute the aeroheating over a relatively larger area especially at the stagnation point $[1,8$ 10]. Consequently, blunting the forebody is viewed as the primary alternative in hypersonic regimes [11]. In fact, supersonic and hypersonic vehicles such as missiles, interplanetary space missions, space planes, launch missiles usually have blunt shapes [10,12]. Besides, in some applications, blunting the nose becomes a favored design requirement on its own. For example, blunt noses are recommended for better accommodation and operation of crew or seeker devices (optical, infrared, radar) with a more efficient usage of the available volume $[2,13]$. Blunting the forebody of long missiles is sometimes adopted to make the use of shorter launchers and launch tubes more cost-effective [14]. Moreover, the volumetric efficiency of the blunt noses is higher than that of their pointed counterparts [15].

Obviously, designing a vehicle that simultaneously satisfies both minimum drag and aerodynamic heating is not a simple task and there must be a tough trade-off between these two vital requirements. The design of the re-entry vehicles such as reusable launch vehicles, long-range and ballistic missiles is rather complicated. On one hand, it is desired to use a pointed forebody to minimize the drag for less fuel consumption during the take-off (ascent) phase. On the other hand, due to excessive heating loads during the descent phase, a blunt forebody is advantageous to yield the desired vehicle deceleration as well $[1,9,10,16]$.

In the high speed regimes, a blunt forebody yields a strong detached bow shock wave ahead of it. This shock wave is responsible for the elevated pressure and aeroheating levels attained by the downstream flow. Thus, it was believed that the excessive drag and heating loads can be reduced by altering the flowfield pattern ahead of the blunt forebody so as to eliminate the strong shock wave or replace it with a weaker system of shock waves. A variety of techniques have been implemented in this regard. These techniques include spikes and aerodisks, focused gas jet, laser or microwave beams upstream of the nose stagnation point, energy deposition using plasma torch, arc discharge, dc corona discharge, and even supersonic projectiles fired ahead of the blunt forebody [10]. Out of these varieties of techniques, the use of spikes proved to be the simplest and the most effective technique in reducing both drag and aerodynamic heating [15]. It is considered as a compromise of two requirements namely, lower aerodynamic heating for re-entry and lower drag for atmospheric flights [17].

The spike is simply a thin cylindrical rod of fixed length mounted at the stagnation point of the blunt forebody and projected in the upstream direction. In some applications, protruding and telescopic spikes of variable length were implemented $[14,18]$ while in other applications, a spike attached to the re-entry vehicle was ejected in the re-entry phase only [19]. Conceptually, a spike introduces two major modifications to the flowfield upstream of the blunt forebody. Firstly, it replaces the strong detached shock wave with a system of weaker oblique shock waves. Secondly, it acts as a "flow separator"; the spike encourages the separation of the boundary layer from its surface and the creation of a shear layer. The latter 
propagates downstream, reattaches on the blunt forebody surface, and envelopes a zone of recirculation in which the flow attains low pressure and velocity values. This zone screens a considerable portion of the blunt forebody surface and results in a significant drop in surface pressure and temperature. Only at the zone of shear layer reattachment on the blunt forebody, the local heating rate and surface temperature attain high values. In addition, to turn the flow outside the shear layer parallel to the forebody surface, a shock wave is created at the reattachment zone. Immediately downstream of this reattachment shock, the flow pressure attains high local values. Nevertheless, the overall effect is a significant reduction in both drag and the aerodynamic heating.

To further enhance the effectiveness of the spike, a relatively larger tip of a variety of designs, called the aerodisk, can be used. An aerodisk mounted at the tip of a spike of a fixed length has the role of adding further reduction in both drag [20] and aerodynamic heating [21] over a wider range of Mach numbers [6] and incidence angles [16]. It can also compensate the drag reduction in cases when a shorter spike is to be used [15]. The typical features of the flowfield associated with unspiked and aerodisk-spiked blunt bodies in high flow speeds are illustrated in Fig. 1. These features were given various terminologies in the literature. For instance, the oblique shock ahead of the spike/ aerodisk tip was referred to as conical shock wave [18,22], bow shock [6], and flow separation shock [10]. Nevertheless, this shock can be conical or bowed (depending on the spike tip/ aerodisk geometry) and can take place at or upstream of separation point. Hence, to avoid confusion, the term "foreshock" is introduced to refer to the shock wave at the spike/aerodisk tip whereas the term "separation shock" is used to refer to the shock wave created due to shear layer separation. Similarly, the reattachment shock was referred to as the recompression shock [21]. For the sake of unifying the definitions, the terminologies illustrated in Fig. 1 are suggested.

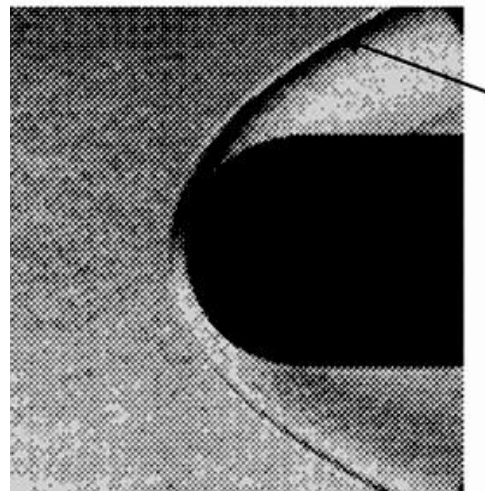

(a)

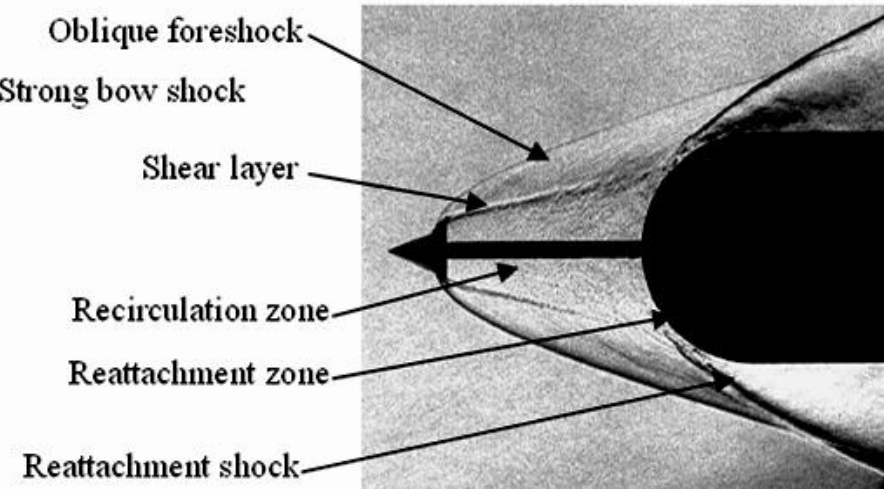

(b)

\section{Figure 1 Macroscopic features of the flowfield ahead of a blunt forebody in hypersonic speeds (a) without [23], and (b) with the spike/ aerodisk [4]}

The flow outside the recirculation zone moves past the slender (nearly conical) shear layer and the shoulder of the blunt forebody. Eventually, mounting the spike/ aerodisk has the role of virtually transforming the blunt forebody into a more slender "effective" body [19]. As a consequence, the overall fineness ratio of the vehicle increases with a slight weight penalty $[13,19]$. In addition, mounting the spike leads to a reduction in pressure and heating levels on the rear and base parts of the body as well [11]. It is also known that the use of spikes protects the forebody from other problems associated with elevated temperatures in the hypersonic regime such as dissociation, ionization, and recombination of air. Only at the very vicinity of the spike tip, these reactions have effect whereas the flowfield around the forebody remains unaffected such that the general laws of perfect gases apply [11] which simplifies the 
numerical simulation as well. Moreover, at angles of attack, the spike has the effect of increasing the lift $[2,19,24]$ and slightly shifting the vehicle's centre of pressure upstream which enhances its maneuverability [4,25].

The benefits of using spikes with high speed vehicles are not limited to the aerodynamics and flight mechanics features as mentioned above. It is interesting to note that, in the context of high speeds vehicles' design, spikes were also implemented to accomplish other operational requirements. For instance, a spike can be used as a Pitot tube to measure the flight speed. In planetary vehicles, spikes were used as probes to collect gas samples [26] whereas in antitank projectiles, spikes provide a stand-off distance for a more efficient warhead detonation [27]. However, the use of spikes is subject to some limitations. Clearly, the spike produces no significant effect if it is very short [26], in low Mach number values [2,28], or in rarefied conditions [29]. In addition, the spike becomes effective only if the forebody is blunt enough to generate a bow shock wave ahead of it [30]. Moreover, structural and rigidity considerations should be taken into account in cases of very long spikes and measures should be taken to reduce the intensive heating loads at the spike tip [31]. Whether the attachment of the spike at the tip of the blunt forebody nose will affect the function of any seeker devices should also be considered [32]. In addition, the benefits of using the spikes diminish as the incidence angle increases [6,10]. It was thus recommended that the use of spikes should be limited to vehicles that perform low maneuvers during flight [2].

In addition, the use of spikes has a number of potential problems that should be carefully considered. Obviously, the upstream shift of the vehicle's centre of pressure reduces its stability [16]. Besides, the pitching moment acting on the vehicle increases which invokes some additional considerations to compensate [16,21]. Furthermore, the flow separation induced by the spikes was found to cause aerodynamic undamping of some oscillation modes during flight [14]. Moreover, under certain flight conditions and blunt forebody/ spike configurations, the flow can become highly unstable which invokes some problems such as fluctuations in surface pressure and heat flux [19], elevated acoustic and structural dynamic loads [18], bending of the spike [14], and flight disturbances and control complications $[24,25]$. These problems can get rather worse due to the hysteresis of flow separation taking place during the extension and retraction of protruding and telescopic spikes [18,33]. In addition, under certain condition, parts of the blunt forebody downstream of the reattachment zone are exposed to excessive aerodynamic heating loads [19]. In fact, aerodynamic heating reduction is not always guaranteed and, in some cases, the total heat transfer to the blunt forebody can be doubled in the presence of the spike mainly due to the elevated heating in the reattachment zone [34].

\section{Literature Review}

In the open literature, a huge body of studies concerning the spiked bodies aerothermodynamics can be found. Almost all these studies are discussed in the present section and summarized in Appendix A. For a clearer survey, these studies are classified into four categories. The studies focusing on the general features of the spiked bodies aerothermodynamics are illustrated first; the experimental studies followed by the numerical simulation studies. Next, the studies (both experimental and numerical) concerning the flow unsteadiness associated with the spiked bodies are discussed. Finally, some interesting studies of the nonconventional usages of spikes are presented. In what follows, unless otherwise stated, the value of Reynolds number is calculated based on the freestream conditions and the main body's diameter. 


\section{A. Experimental studies}

The studies related to the spiked bodies' aerodynamics can be traced back to 1947 [13]. In the Langley Pilotless Aircraft Research Division, a number of firing tests were executed on blunt and sharp nosed bodies in Mach numbers 0.95 to 1.37. It was proposed that mounting a thin rod with a relatively larger conical tip (the aerodisk, called the "windshield" at that time) on the blunt forebody could increase the effective fineness ratio of the latter with a slight weight penalty. Based on firing tests measurements, Alexander [13] reported a slight drag reduction using the conical "windshield" which was still higher than that of the pointed forebody in Mach 1.37. A step forward was made by Moeckel [35] four years later. He measured the surface pressure on a spiked parabolic forebody with a hemispherical nose in a Reynolds $2 . \times 10^{5}$ (based on the nose diameter), Mach 1.76, 1.93 freestream. A plain conically pointed spike (called the "projecting rod") whose length varied from 1 to 12 times the forebody nose diameter was used.

The comprehensive study by Mair in 1952 [36] is probably the first landmark study in the field. He experimentally examined the flow around spiked flat cylindrical and hemisphere cylindrical models in a Mach 1.96 , Reynolds $1.65 \times 10^{5}$ flow. A conically pointed spike (called the "probe") was utilized and its length-to-model diameter ratio, $L / D$, was varied up to 6 . Mair presented a very fine anatomy of the flowfield around the spiked bodies and thoroughly discussed the impact of the spike length on the flowfield. He also measured the surface pressure and the corresponding drag on a model with $L / D=1.44$. Mair was the first to record a sign of flow instability around spiked bodies. For the flat cylindrical models and for a certain range of spike length, a significant flow instability is invoked in which the shock wave at the spike tip changes its shape in a self-sustained manner. Mair proposed the first explanation of this form of "flow oscillation" based on the pressure difference between the flow downstream of the reattachment shock and the flow inside the recirculation zone. In the same year, Jones [37] investigated the flow around conical models with a hemispherical nose at a Mach of 2.72. A sharp pointed "protruding rod" which length varied from 1 to 6 times the forebody nose radius was used. Jones was also the first to point out that only one streamline can stagnate on the forebody surface at the reattachment point; this streamline was not given a specific term.

The term "spike" was first used in 1954 by Piland and Putland [28]. They analyzed the results of firing tests in Mach numbers ranging from 0.7 to 1.3 and Reynolds numbers from $1.44: 2.64 \times 10^{5}$ flight conditions. The study involved (among others) projectiles of hemispherical noses with and without sharp pointed spikes of two different lengths. They concluded that no drag reduction was achieved for that range of Mach numbers regardless to the spike length. Stalder and Nielsen [34] conducted the first investigation of the aerothermodynamic effects of the spikes. They measured the heat transfer to a hemisphere cylindrical model in a Mach number ranging from 0.12 to 5.04 and the Reynolds number ranging from $1.55: 9.85 \times 10^{5}$. The model was equipped with spikes of pointed tip, flat aerodisk, and conical aerodisk and their $L / D$ ratio varied from 0.5 to 2 . They reported that, regardless to the spike length and tip geometry, heat transfer to the spiked model was as twice as that of the unspiked model. They argued that the cause of heat transfer rise was the high turbulence level in the dead air zone and the impingement of turbulent shear layer on the model surface.

Jones [38] used the "windshield" to reduce the drag on a hemisphere conical model in a Mach 2.72, Reynolds $1.83 \times 10^{6}$ flow. The "rod" was $0.415,1.125$, and 1.464 times the model nose diameter. To study the role of their shapes, conical windshields with variable lengths and 
angles were examined. The drag reduction was found to depend on both rod length and windshield geometry and for long rods, the windshield was found to lose its benefits in reducing the drag. Beastall and Turner [33] conducted an investigation on flat cylindrical models in a Reynolds $1.125 \times 10^{6}$, Mach $1.5,1.6$, and 1.8 flow. The models were equipped with spikes of pointed ogive tips along with conical aerodisks of variable vertex angles. A protruding spike with $L / D$ up to 4.7 was used. They reported a hysteresis phenomenon in the flow field evolution. The drag on the models for a specific spike length was found to depend on whether the spike was extended or retracted. Apart from the "violent oscillations" first recorder by Mair, Beastall and Turner recorded a new type of flow unsteadiness associated with loner spikes. This "mild oscillation" type was characterized by small oscillations of the shear layer. Hermach et al. [39] used the term "pulsating flow" to refer to the violent oscillations. They focused on the impact of this type of flow unsteadiness on the aerothermal characteristics of the spiked bodies. Pointed spikes of variable tip design and $L / D$ ratio up to 2 were fitted on a flat cylindrical model in a Mach 3.5, Reynolds $1.73 \times 10^{6}$ flow. It was found that, at certain optimum spike length, pulsating flow could produce up to $22 \%$ reduction in the temperature recovery factor compared to the laminar boundary layer. In addition, the frequency of pulsating flow was found to monotonically decrease by increasing the spike length. Bogdonoff and Vas [11] undertook an important experimental investigation of pressure and heat transfer distribution on spiked bodies. Two models namely, flat cylindrical and hemisphere cylindrical models were tested in a Mach 14, Reynolds $3.6 \times 10^{5}$ Helium flow. The role of varying the length of a pointed spike ( $L / D$ up to 8 ) was investigated. They argued that the heat transfer to the spiked model is significantly reduced if the separated shear layer remains laminar until reattachment. Both types of flow unsteadiness were recorded for flat cylindrical models.

Another milestone in the field was set by Crawford in 1959 [23]. He conducted an extensive experimental investigation of drag and aerodynamic heating on a spiked hemisphere cylindrical model in Mach 6.8 flow. The model was equipped with a pointed spike of variable length ( $L / D$ up to 4 ). The role of Reynolds number was first investigated in this study by varying its value from $0.12 \times 10^{6}$ to $1.5 \times 10^{6}$ based on freestream conditions and model diameter. In all cases, the model's surface pressure and heat flux attained peak values at the reattachment point. The pressure peak remained well below the stagnation pressure whereas the peak heat flux ranged from half (at the lower bound of Reynolds number) to double (at the upper bound) the heat transfer value at the stagnation point of the unspiked model for all spike lengths. Maull [9] conducted the first attempt to address the impact of modifying the body shape on the flowfield structure. He investigated the role of rounding the shoulder of a spiked flat cylindrical model on the flow oscillations in Mach 6.8, Reynolds $8.5 \times 10^{4}$ flow. A pointed spike of a variable length ( $L / D$ up to 3 ) was used and the roundness (ratio of shoulder radius to model diameter) of the models' shoulders varied from 0 (sharp shoulder) to 0.5 (hemisphere cylindrical model). Maull refined the mechanism of boundary layer separation over the spike length based on the pressure equilibrium on both sides of the separation shock wave. Maull also clarified the mechanism of flow stability based on the mass flow equilibrium between the flow scavenged by the shear layer and that reversed inside the dead air zone. The governing factor was argued to be the flow turning angle on the model's face at reattachment. A hemisphere cylindrical model was found to yield a stable flow regardless to the spike length.

Another landmark was established by Wood [22]. He was the first to investigate the variation in the flowfield structure by changing both the model geometry and the spike length in Mach 10 and Reynolds number $0.5 \times 10^{5}$ freestream. The model was a cone cylindrical model which 
vertex angle varied from $30^{\circ}$ to $180^{\circ}$ (flat cylinder) while the used pointed spike had a variable length ( $L / D$ up to 5 ). Wood classified the flow pattern around spiked conical models into five categories depending on the spike length and the model's semi-apex angle. Wood was the first to use the term "dividing streamline", first introduced by Chapman [40], to refer to the streamline that links the separation and reattachment points of the share layer at steady flow conditions. The role of spikes in reducing drag and heat transfer was also supported by Wagner and Pine [8] in a Mach 19.4, Reynolds $0.3 \times 10^{6}$ with Helium flow. Among other models representing the common re-entry vehicle designs, blunt parabolic cylindrical and hemisphere cylindrical models were equipped with a pointed spike of variable length $(L / D$ up to 5). The performance of spikes at incidence in very low Reynolds number environments (similar to those experienced by planetary vehicles) was investigated by Sims et al. [29]. The drag on two models namely, flat cylinder and highly blunt cone in a Mach 10.1, Reynolds 194 Nitrogen flow was measured. The models were equipped with a pointed spike of variable length ( $L / D$ up to 5 ).

Another important landmark in the field was established by Holden [30]. In this fine experimental investigation, focus was made on the heat transfer to spiked models in Reynolds $0.27 \times 10^{6}$, Mach 10 and 15 flow. Three models namely, hemisphere cylinder, flat cylinder, and cone cylinder were investigated. The semi-vertex angle of the conical nose had the values of $30^{\circ}, 45^{\circ}, 60^{\circ}$, and $75^{\circ}$ while the $L / D$ ratio of the pointed spike varied up to 4 . For cone cylindrical models, Holden extended and refined the classification of flow patterns around spiked models first established by Wood [22] to higher Reynolds and Mach number values. $\mathrm{He}$ also recorder the mild oscillations on conical models for the first time and added a new pattern corresponding to it. Holden showed that the peak local heat transfer rate at the reattachment point is in a direct proportionality with reattachment angle. The latter is dictated by both the spike length and cone vertex angle.

Khlebnikov [41] focused on measuring the heat transfer to spiked spherical models in a Mach 3 , Reynolds $1.4 \times 10^{6}$ flow. The model was equipped with spikes of different lengths ( $L / D=0.283: 1.78$ ) whereas conical and pyramidal aerodisks were fitted at their tips. It was concluded that, the value of peak heat flux varies inversely with its distance from the spike root. McGhee and Staylor [26] investigated the role of mounting very short pointed spikes to blunt conical models in Reynolds $1.83 \times 10^{6}$, Mach 3, 4, and 6 flow. Their experiments involved two conical models with a vertex angle of $120^{\circ}$ and blunt nose radii of 0.25 and 0.5 the base radius. The spike length varied from 0.055 to 0.083 the model's base diameter. Three spikes with different conical tips $\left(20^{\circ}, 30^{\circ}\right.$, and $40^{\circ}$ semi-vertex angles) and two different diameters ( 0.044 and 0.011 of the model base diameter) were tested and the role of $0^{\circ}, 2^{\circ}$, and $5^{\circ}$ incidence was investigated as well. With such short spikes, the flow features were correlated to the ratio of spike length to standoff distance of the bow shock wave ahead of the unspiked model. The impacts of both spike tip angle and diameter on pressure distribution on the models were found insignificant. Staylor [42] extended this investigation to Mach 9.6, Reynolds $6 \times 10^{4}: 23 \times 10^{4}$ flow and the study included results of up to Mach 20 flow. A third model of a pointed nose was added, the spike length was extended up to 4 times the standoff distance of the unspiked model, and focus was made on the heat transfer characteristics on the models. The role of spike length was recently confirmed by Humieres and Stollery [43]. They experimentally investigated a re-entry vehicle model of a spherical cap and conical afterbody in a Mach 8.2 , Reynolds $9 \times 10^{6}$ flow. They quantitatively confirmed the similarity between spiked bodies and solid cones first addressed by Mair [36]. 
After the studies of Alexander [13] and Jones [38], the superiority of the aerodisks in drag reduction compared with the plain spike was explained and discussed in many studies $[16,20,21]$. In [20], a blunt ogive cylindrical model was equipped with an extensible "telescoping" spike with a blunt aerodisk at its tip. The freestream conditions corresponded to transonic (Mach up to 1.2, Reynolds $8: 12 \times 10^{6}$ ) and supersonic (Mach up to 3, Reynolds $4.7: 7 \times 10^{6}$ ) flow. It was proposed that, the further drag reduction is caused by the merge of two dead-air zones; the one ahead of the main body and the one generated at the wake of the aerodisk.

In the rich experimental investigation by Motoyama et al. [21], pressure and heat flux distributions along a spiked hemisphere cylindrical model in a Mach 7, Reynolds $4 \times 10^{5}$ flow were recorded. Moreover, the variation of drag and pitching moment coefficients with incidence angles (up to $8^{\circ}$ ) were measured. In addition to a plain spike with conical, rounded, and flat ends, hemispherical and flat aerodisks of two different sizes and two spike length ( $L / D=0.5$ and 1.0) were tested. Contributions of both the model and the spike/aerodisk in the total pressure drag were also separately addressed. The study focused on the impact of the spike length and tip design on the heat transfer to the main body. The comprehensive investigation by Kalimuthu et al. [16] also confirmed the advantages of using aerodisks. Drag, lift, and pitching moment acting on a hemisphere cylindrical model in a Mach 6, Reynolds $9.44 \times 10^{5}$ with incidence (up to $8^{\circ}$ ) freestream were measured. The spikes used had a variable length ( $L / D=1.5$ and 2$)$ and, in addition to a pointed plain tip, hemispherical and flat aerodisks were examined as well.

Even without using an aerodisk, modifying the tip of a plain spike was proved to have a strong impact on its performance. For instance, Milicev et al. [25,44] experimentally examined a hemisphere cylindrical model in a Mach 1.89 , Reynolds $3.8 \times 10^{5}$ flow at incidence (from $-4^{o}$ to $10^{\circ}$ ). The model was equipped with four spikes having the same length $(L / D=1)$ and different shapes namely, pointed cylindrical, rounded cylindrical, and conical (with two different vertex angles). It was concluded that the spike with a rounded tip produces that maximum drag reduction. Recently, Kalimuthu et al. [45] undertook a similar study. A hemisphere cylindrical model was studied in a Mach 6. The model was equipped with a spike of a rounded tip and ( $L / D=1.5$ and 2.0) and the variation of lift, drag, and moment coefficient with incidence angle (up to $8^{\circ}$ ) was investigated. Huebner et al. [6] focused on finding the range of incidence angles within which the spike would perform the best in terms of drag and aerodynamic heating reduction. The pressure and wall temperature distribution along a cylindrical model capped with a smaller hemisphere were thoroughly measured. The freestream conditions corresponded to a Mach 6.06, Reynolds $2.67 \times 10^{6}$ flow and the incidence angle varied from $0^{\circ}$ to $40^{\circ}$. A flat aerodisk was fitted at the tip of the spike that had an $L / D$ ratio of 3 .

\section{B. Numerical Simulation Studies}

Numerical studies of the spiked bodies started as early as 1980s. Myshenkov [46] applied the solution of the complete Navier-Stokes equations using the finite-difference approach in a two-dimensional axisymmetric computational domain. The freestream conditions corresponded to Mach 0.5: 3 Reynolds $1 \times 10^{3}: 1 \times 10^{4}$ and Mach 2, Reynolds 3.6: $1 \times 10^{5}$ flows. The model was a flat cylinder equipped with a pointed spike with a variable length (up to $L / D=3.25$ ) and the roles of Mach number, Reynolds number, and spike length were discussed. Paskonov and Cheraneva [47] solved the complete unsteady Navier-Stokes 
equations in a two-dimensional axisymmetric flowfield around cone cylindrical (semi-vertex angles of $70^{\circ}$ ) and flat cylindrical models equipped with pointed spikes of variable length (up to $L / D=1$ ). The freestream conditions corresponded to Mach 2: 6, Reynolds 100: 500 flows. Karlovskii and Sakharov [48] solved the unsteady Euler equations of an inviscid flow in a two-dimensional axisymmetric computational domain. The model had a truncated conical design whereas the spike had a hemispherical tip and a variable length (up to $L / D=1$ ). The freestream conditions corresponded to Mach 3: 8 flows. Shoemaker [2] solved the twodimensional unsteady Navier-Stokes equations and the results was validated with some experimental data on blunt bodies. Shoemaker studied two models namely, blunt cone cylindrical and hemisphere cylindrical in a Mach 2.5 freestream conditions. The spike had a variable length $(L / D=2: 9)$ and a biconical aerodisk at its tip.

Turbulence models were implemented in the numerical scheme by the 1990s. The algebraic Baldwin-Lomax two-layer zero-equation model was widely used at that time $[3,27,49,50]$. In [3], White adopted the finite volume approach to solve the Navier-Stokes equations in the axisymmetric domain around two spiked models in Mach 4 farfield conditions. The models had hemisphere cylindrical and hemisphere capped cylindrical designs and the flat spike used had a variable length $(L / D=0.875$ and 1.3$)$ and the results were validated with experimental measurements on the same models. Mikhail [27,49] solved the unsteady Navier-Stokes equations in the two-dimensional axisymmetric flowfield around a complete spiked projectile in a Mach 1.72. The spike had flat and conical tips and its $L / D$ ratio was 1.08 and 1.47. Results were validated with experimental measurements on the same projectile. In [50], Hur et al. solved the complete time-dependent Navier-Stokes equations around complete spiked projectiles with fins. The projectiles had hemisphere cylindrical and flat cylindrical design equipped with flat spike whose $L / D$ ratio was 1.42 and the freestream conditions corresponded to Mach 2.23, Reynolds $1.716 \times 10^{6}$ and Mach 3, Reynolds $7 \times 10^{6}$, zero incidence flow. Density contours and velocity vectors were calculated and the results were validated with experimental data on the same model.

The results of the rich experimental investigation by Crawford [23] were used to validate the numerical results by many researchers. In their comprehensive numerical investigation, Yamauchi et al. [51] tested a spiked hemisphere cylindrical model in Mach 2.01, 4.15, and 6.8 , Reynolds $1.4 \times 10^{5}$ flow. The model was equipped with a plain pointed spike with a variable length ( $L / D=0.5,1$, and 2 ) and the Navier-Stokes equations were solved assuming laminar steady flow conditions on an axisymmetric computational domain. Mehta conducted a number of numerical studies $[5,7,52]$ on the same model namely, a hemisphere cylindrical model equipped with a pointed spike. In all studies, he solved the unsteady Navier-Stokes equations in an axisymmetric computational domain and the flow was assumed laminar. In [5,7], he reproduced the same numerical investigation by Yamauchi et al. and made validations with their results. Asif et al. [53] reproduced numerically the experimental investigations of Crawford [23] and Milicev et al. [25]. They also compared their results with those of Mehta [5] and Yamauchi et al. [51]. Gauer and Paull [15] used the results of Crawford [23] to validate their extensive numerical investigation. The model tested had a blunt conical shape and the spike had a variable length ( $L / D$ varied from 1 to 4 ). In addition to pointed and rounded tips, a hemispherical aerodisk (with two different sizes) was attached to the spike tip. The farfield conditions corresponded to Mach 5, 7, and 10 freestream conditions. And the results were also validated with the calculations in [5,51]. In addition to Crawford's experiments, many other experimental investigations were reproduced numerically. For instance, Srivinasan and Chamberlain [54] reproduced numerically the experimental investigation of Reding and Jecmen [55]. Similarly, Kurbatskii and Montanari 
[24] reproduced the experiments of Gnemmi et al. [4] and Huebner [6]. Mehta [12] reproduced the experiment conducted in [16] using a laminar, steady, axisymmetric numerical model.

The commercial CFD codes were also used to assist and support the experimental results conducted by many researchers such as Gnemmi et al. [4,57] and the co-researchers of P. K. Reddy. [1,10,56,58]. Gnemmi et al. [4,57] experimentally studied the flow around spiked hemisphere cylindrical models in a Mach 4.5 flow at incidence (up to $24^{\circ}$ ). The spike had a fixed length $(L / D=1)$ whereas flat, spherical, and biconical aerodisks fitted at its tip were examined. The experiment was reproduced numerically in a three-dimensional computational domain around the models. The co-researchers of Reddy focused on highly blunt spiked models in a Mach 5.75, Reynolds $1.5 \times 10^{5}$ freestream conditions. In [1], the model was equipped with a flat aerodisk and the spike had a fixed length $(L / D=1)$. They recorded the variation of drag coefficient with the incidence angle (up to $12^{\circ}$ ) and the results were validated with numerical simulation results. The study was extended in [10] to include more spike tip designs namely, hemispherical aerodisk, flat and pointed plain spike. The spike had a variable length ( $L / D=0.2,0.5,0.7$, and 1$)$. The variation of surface pressure and heat flux with spike length and the impact of incidence angle on the total drag were discussed and the results were reproduced numerically. The study was extended to a Mach 8 freestream on the same model at zero incidence in [58]. The study focused on the drag reduction only and the results were compared with a numerical simulation. In [56], focus was made on the flow unsteadiness around the same model. The accuracy of the commercial CFD codes in predicting the flowfield features around spiked models were discussed in the interesting work by Roveda [59]. His study focused on comparing the performance of Cobalt and CFD++ codes against Fluent simulation results by Kurbatskii and Montanari [24] and the experimental findings by Heubner et al. [6] and Gnemmi et al. [4].

\section{Studies Focusing on the Flow Unsteadiness around Spiked Bodies}

In the literature, a number of studies were completely devoted to investigating the flow instability around spiked bodies; they are discussed below.

The two distinct modes of flow instability associated with spike blunt bodies namely, violent and mild oscillations, were given new terminologies by Kabelitz [60] in 1971. The violent mode was termed the "pulsation mode" and the mild mode was termed the "oscillation mode". However, in the Russian literature for some years later, oscillation and pulsation modes were termed as pulsation of the first kind and pulsation of the second kind, respectively. For instance, Antonov and his co-researchers conducted a number of experimental investigations on unsteady flow around spiked models [61,62-64]. In [61], they investigated the flow around a spiked flat cylindrical model in a Mach 6, Reynolds $1 \times 10^{6}$ freestream. The model was equipped with a pointed spike of a varying length ( $L / D$ up to 3 ) and the study focused on pressure and heat transfer fluctuations on the model surface in both modes of unsteadiness. The most important finding of this study is the determination of the range of each mode of unsteadiness. The first kind (oscillation) takes place when $3>L / D>1.4$ while the second kind (pulsation) takes place for $0.3 \leq L / D \leq 1.4$ and the flow becomes steady elsewhere. This

investigation was extended to Mach 2 to 6 , Reynolds $6 \times 10^{4}$ to $3 \times 10^{6}$ flow in $[62,63]$. The model tested had a cone cylindrical shape with the cone semi-vertex angle varying from $45^{\circ}$ to $120^{\circ}$. The $L / D$ ratio of the pointed spike used varied up to 5 whereas its diameter varied from 0.06 to 0.3 the model diameter. 
A landmark study was conducted by Antonov et al. [64], in which they implemented the same freestream conditions and used the same models of their previous studies. In this work, they managed to capture the evolution of pulsation flow mode for the first time and determined its cycle, mechanism, and cause based on scientific evidence. Kenworthy [65] also examined a flat cylindrical model in a Mach 2.1, Reynolds $0.12 \times 10^{6}$ flow. The model was equipped with a pointed spike with $L / D=1$. In addition, Panaras [66,67] independently proposed the same conclusions as Antonov et al. and proposed the same description and explanations. The cause of pulsation as explained by Antonov et al. [64] and Kenworthy [65] is different and more comprehensive than that was first proposed by Mair [36] and prevailed in the later studies. In fact, the two explanations are based on the feeding or air from an external source. The only difference lies in the source of this air supply. While Mair assumed that the air is coming directly from behind the bow shock, Antonov et al. proved and Kenworthy confirmed that the air is coming from behind the oblique separation shock. Panaras highlighted that the flow behind the bow shock is definitely subsonic whereas the flow inside the separation zone is supersonic. Hence, the only possible source of the "filling" flow is from behind the weak oblique shock wave. Consistent with [61], Panaras [66] showed that pulsation mode is switched to oscillation mode if the spike length exceeds 1.4 times the model diameter (in a Mach 6 flow). The same explanation of pulsation mode was confirmed by Zapryagaev et al. $[68,69]$ who investigated flat cylindrical models equipped with pointed spikes of $L / D$ ratio varying up to 1.5. In [68], freestream conditions corresponding to Mach 2 and 3 and Reynolds 2.4:5 $\times 10^{6}$ were applied and was extended in [69] to a Mach 6.08, Reynolds $6.35 \times 10^{5}$ flow. The pulsation mode was also investigated by Hankey and his co-researchers $[18,70,71]$. They studied the Mach 3, Reynolds $4 \times 10^{5}$ flow around spiked truncated conical model (cone half angle is $9^{\circ}$ ) and the spike used had a hemispherical tip and its $L / D$ ratio was 0.75 . The most important contribution of this group of researchers is the implementation of numerical techniques (for the first time) in solving the flowfield around spiked models. In [70,71], they solved the unsteady laminar Navier-Stokes equations on the two-dimensional axisymmetric flowfield using the finite difference approach and the results were validated with their own experimental findings. For this model, the pulsation mode was found to occur in the range $0.875 \geq L / D>0.25$. The calculated mean pressure at the model shoulder increased with the spike length, reached a maximum (about 17 times the freestream pressure) at $L / D=0.875$ and dropped rapidly afterwards. The density contours and velocity profiles were also calculated during a complete period of pulsation. In [18], an experimental investigation was conducted on the same model with focus on the effect of using an extensible spike. A hysteresis phenomenon was found to take place in the range $0.85 \geq L / D>0.7$.

The most important contribution of Kenworthy [65] is the explanation of the cycle, mechanism, and cause of the oscillation mode. According to Kenworthy, the cause of flow oscillation mode is a continuous pressure imbalance on both sides on the shear layer at the reattachment point. Hence, a mass balance is established between the air scavenged out from the separation zone and the air reversed into it. Feszty et al. [72-75] reproduced numerically the experimental investigation of Kenworthy [65]. They implemented the solution of the unsteady laminar Navier-Stokes equations in an axisymmetric domain around the spiked model. In [72], the pulsation mode was investigated. The freestream conditions corresponded to Mach 2.21, Reynolds $0.12 \times 10^{6}$ while the $L / D$ ratio was 1 . In [74], the pulsation mode around the same model in a Mach 6, Reynolds $0.13 \times 10^{6}$ flow was investigated. Focus was made on flow oscillation mode in [73]. The same model with a longer spike $(L / D=2)$ in a Mach 6, Reynolds $0.13 \times 10^{6}$ flow was investigated. The explanation of the flow oscillation mode and its mechanism as proposed by Kenworthy [65] were confirmed using the numerical 
tools. The hysteresis phenomena recorded by Kenworthy [65] was reproduced numerically in [75]. The freestream conditions corresponded to Mach 2.21 , Reynolds $0.12 \times 10^{6}$ while the $L / D$ ratio of the extensible spike was ranging from 1.25 to 2.4. Panaras and Drikakis [17] reproduced numerically the experiments of Panaras [67], Kenworthy [65], Calarese and Hankey [18], and Crawford [23]. The features of oscillation, pulsation, and hysteresis flow were confirmed.

\section{Other Interesting, Non-Conventional Studies}

Apart from the "main stream" studies illustrated above, a number of studies introduced some different implementations of spikes with blunt bodies and possible techniques to further enhance their performance. In what follows, these studies are discussed. Instead of putting the whole model at incidence, Thurman [76] showed that lift could be generated by slightly deflecting the spike alone with respect to the model's symmetry axis. He measured both lift and drag acting on a hemisphere cylindrical model equipped with a pointed spike $(L / D=4)$ in a Mach 11.76, Reynolds $1.4 \times 10^{4}$ flow and the spike deflection varied up to $7^{\circ}$. A more advanced study based on almost the same idea was conducted by Schulein [77]. He introduced the concept of "pivoting spike" in which the spike is maintained aligned with the freestream direction while the whole body is at incidence. He experimentally examined the pivoting spike in Mach 2, 3, and 5 with up to $30^{\circ}$ incidence. Instead of using a spike, Guy et al. [32] suggested attaching the aerodisk at a distance from the model using a strut thus clearing the nose area of the model; such design was recommended in some practical applications (such as missiles with heat seeker devices). The study involved a hemisphere cylindrical model and a number of conical aerodisks of different vertex-angles and base diameters in Mach 0.92 and 1.62 freestream conditions.

To further enhance the effectiveness on spikes, Khlebnikov [78-80] suggested rotating the spike about its axis. Flat cylindrical, conical, and spherical models were examined in Mach 3, Reynolds $0.8: 1.6 \times 10^{6}$ flow conditions and the $L / D$ ratio varied up to 1.68 . A plain pointed spike and a wedge-shaped aerodisk, and incidence angles $0^{\circ}$ and $10^{\circ}$ were tested. Another technique was suggested to further boost the effectiveness of the spikes namely, the addition of external injection/ burning of gas jet. This technique was first introduced by Reding and Jecmen [55]. They experimentally investigated hemisphere cylindrical and blunt ogive cylindrical models in a Mach 2.2, Reynolds $5.23 \times 10^{6}$ freestream. The $L / D$ ratio of the used spike varied from 1 to 1.875 and a flat aerodisk was fitted at the spike tip. Lateral jets of hydrogen were injected from orifices in the side face of the aerodisk. A similar (but briefer) investigation was conducted by Jiang et al. [31]. A hemisphere cylindrical model equipped with a blunt tipped spike ( $L / D=1$ ) was examined in a Mach 6, Reynolds $1.98 \times 10^{7}$ freestream at zero and $4^{\circ}$ incidence. A lateral jet of air was applied at the shoulder of the spike's rounded tip. It was believed [31] that the use of jet broadens the range of incidence angles within which the spike will be effective in reducing the drag (such as that discussed by Huebner [6]).

\section{Conclusions and Future Perspective}

Since their introduction to the design of high-speed vehicles in 1947, spikes and aerodisks have gained much increasing interest from the researchers. The naive modification of the vehicle's design by adding a thin rod at the vehicle's stagnation point yields a flowfield full of interesting details including, flow separation, shock-shock, and shock-layer interactions. The present paper is intended to give the readers the up-to-date advances in the field of spikedbodies aerothermodynamics. The previous literatures are thoroughly explored and the studies 
that founded our today's knowledge in this field are highlighted. Nonetheless, there exist some areas in this rich field that have not been thoroughly covered. To name a few:

- The mechanism of drag reduction associated with pointed spikes is not clear. In addition, the superiority of aerodisks in reducing the drag was not explained. Apart from [14,20], no comprehensive explanation is presented.

- The impact of the aerodisk on the aerothermal characteristics was not studied.

- The impact of the spike and aerodisk on the base drag of the spiked body was not separately investigated.

- The flow instability around spiked hemispherical forebodies is controversial. While some researchers confirmed the existence of flow unsteadiness [23,51,52], others showed that the flow around such bodies is always stable $[9,11,36]$.

- The concept of the pivoting spike [77] seems promising and invokes more studies.

- The effect of aerodisk rotation [78-80] deserves more focus.

- The bending and vibration of spikes in practical applications [14] are not thoroughly studied.

- Wood [22] showed that rounding the shoulder of flat-faced spiked models could stabilize the flow. This aspect needs further investigations.

- Comparing the effectiveness of spikes and the similar drag reduction devices especially forward-facing jets may be held. A hybrid device can be proposed.

- It is clear that the performance of the spikes depends mainly upon the design of both the spike and the forebody. This invokes a design optimization study aiming for the optimum shape(s) of the of spiked bodies that yield the best performance at different flight regimes.

Some of the areas mentioned above have been studied by the authors. This will be the focus of part II of this work, dealing with the recent advances of spiked bodies aerothermodynamics and up-to-date contributions. Other areas are still open for future researches.

\section{References}

[1] Menezes, V., Saravanan, S., Reddy, K. P. J., "Shock Tunnel Study of Spiked Aerodynamic Bodies Flying at Hypersonic Mach Numbers," Shock Waves, Vol. 12, No. 1, 2002, pp. 197-204.

[2] Shoemaker, J. M., "Aerodynamic Spike Flowfields Computed to Select Optimum Configuration at Mach 2.5 with Experimental Validation," AIAA paper 90-0414, 1990.

[3] White, J. T., "Application of Navier-Stokes Flowfield Analysis to the Aerothermodynamic Design of an Aerospike-Configured Missile," AlAA paper 930968, 1993

[4] Gnemmi, P., Srulijes, J. and Roussel, K., "Flowfield around Spike-Tipped Bodies for High Attack Angles at Mach 4.5," Journal of Spacecraft and Rockets, Vol. 40, No. 5, 2003, pp. 622- 631

[5] Mehta, R. C., "Numerical Heat Transfer Study over Spiked Blunt Bodies at Mach 6.8," Journal of Spacecraft and Rockets, Vol. 37, No. 5, 2000, pp. 700- 703

[6] Heubner, L. D. Mitchell, A. M. and Boudreaux, E. J., "Experimental Results on the Feasibility of an Aerospike for Hypersonic Missiles", AIAA paper, 95-0737, Jan.1995.

[7] Mehta, R. C., "Peak Heating for Reattachment of Separated Flow on a Spiked Blunt Body," Heat and Mass Transfer, Vol. 36, 2000, pp. 277- 283 
[8] Wagner, R. D. and Pine, C. P., "Laminar Heat Transfer and Pressure Distribution Studies on a Series on Re-Entry Nose Shapes at a Mach Number of 19.4 in Helium," NASA TN D-891, 1961

[9] Maull, D. J. "Hypersonic Flow over Axially Symmetric Spiked Bodies," Journal of Fluid Mechanics, Vol. 8, P.4, 1960, pp. 584-592

[10] Menezes, V., Saravanan, S., Jagadeesh, G., and Reddy, K. P. J., "Experimental Investigations of Hypersonic Flow over Highly Blunted Cones with Aerospikes," AIAA Journal, Vol. 41, No. 10, 2003, pp. 1955- 1966

[11] Bogdonoff , S. M. and Vas , I. E., "Preliminary Investigations of Spiked Bodies at Hypersonic Speeds," Journal of the Aerospace Sciences, Vol. 26, No. 2, 1959, pp. 6574

[12] Mehta, R. C., "Flow Field Computations Over Conical, Disc and Flat Spiked Body at Mach 6", AIAA paper 2009-325, 2009

[13] Alexander, S. R., "Results of Tests to Determine the Effect of a Conical Windshield on the Drag of a Bluff Body at Supersonic Speeds," NACA RM L6K08a, January, 1947.

[14] Reding, J. P., Guenther, R. A., and Richter, B. J., "Unsteady Aerodynamic Considerations in the Design of a Drag-Reduction Spike," Journal of Spacecraft and Rockets, Vol. 14, No. 1, 1977, pp. 54- 60

[15] Gauer, M. and Paull, A., "Numerical Investigation of a Spiked Blunt Nose Cone at Hypersonic Speeds," Journal of Spacecraft and Rockets, Vol. 45, No. 3, 2008, pp. 459 $-471$

[16] Kalimuthu, R., Mehta, R. C., and Rathakrishnan, E., "Experimental Investigation on Spiked Body in Hypersonic Flow," The Aeronautical Journal, Vol. 112, No. 1136, 2008, pp. 593- 598

[17] Panaras, A. G. and Drikakis, D., "High-Speed Unsteady Flows around Spiked-Blunt Bodies," Journal of Fluid Mechanics, Vol. 632, 2009, pp. 69-96

[18] Calarese, W. and Hankey, W., "Modes of Shock-Wave Oscillations on Spike-Tipped Bodies," AIAA Journal, Vol. 23, No. 2, 1985, pp. 185-192.

[19] Album, H. H., "Regarding the Utility of Spiked Blunt Bodies," Journal of the Aerospace Sciences, Vol. 5, No. 1, 1968, pp. 112- 113

[20] Guenther, R. A. and Reding, J. P., "Fluctuating Pressure Environment of a Drag Reduction Spike," Journal of Spacecraft and Rockets, Vol. 14, No. 12, 1977, pp. 705 710

[21] Motoyama, N., Mihara, K., Miyajima, R., Watanuki, T., and Kubota, H., "Thermal Protection and Drag Reduction with Use of Spike in Hypersonic Flow," AIAA paper 2001-1828, 2001

[22] Wood, C. J., "Hypersonic Flow over Spiked Cones," Journal of Fluid Mechanics, Vol. 12, Pt. 4, 1961, pp. 614-624.

[23] Crawford, D. H. "Investigation of The Flow over a Spiked-Nose HemisphereCylinder," NASA TN-D-118, Dec.1959

[24] Kurbatskii K. A. and Montanari, F., "Application of Pressure-Based Coupled Solver to the Problem of Hypersonic Missiles with Aerospikes," AIAA paper 2007-462, 2007.

[25] Milicev, S. S. and Pavlovic, M. D., "Influence of Spike Shape at Supersonic Flow Past Blunt-Nosed Bodies: Experimental Study," AIAA Journal, Vol. 40, No. 5, 2001, pp. 1018- 1020

[26] McGhee, R. J. and Staylor, W. F.," Aerodynamic Investigation of Sharp ConeCylinder Spikes on 120o Blunted Cones at Mach Numbers of 3, 4.5, and 6," NASA TN D-5201, 1969

[27] Mikhail, A. G., "Spike-Nosed Projectiles: Computations and Dual Flow Modes in Supersonic Flight," Journal of Spacecraft and Rockets, Vol. 28, No. 4, 1991, pp. 418 424 
[28] Piland, R. O. and Putland, L. W., "Zero-Lift Drag of Several Conical and Blunt Nose Shapes Obtained in Free Flight at Mach number of 0.7 to 1.3," NACA RM L54A27, March, 1954

[29] Sims, W. H., Boylan, D. E. and Hahn, J. S., "Drag on Blunt Bodies with and without Spikes in Low-Density Hypersonic Flow," AIAA Journal, Vol. 3, No. 2, 1965, pp. 365- 366

[30] Holden, M., "Experimental Studies of Separated Flows at Hypersonic Speeds. Part ISeparated Flows over Axisymmetric Spiked Bodies," AIAA Journal, Vol. 4, No. 4, 1966, pp. 591-599.

[31] Jiang, Z., Liu, Y., Han, G., and Zhao, W., "Experimental Demonstration of a New Concept of Drag Reduction and Thermal Protection for Hypersonic Vehicles," Acta Mechanica Sinica, Vol. 25, No. 3, 2009, pp. 417: 419

[32] Guy, Y., McLaughlin, T. E., and Morrow, J. A., "Blunt Body Wave Reduction by Means of a Standoff Spike," AIAA paper 2001-0888, 2001

[33] Beastall, D. and Turner, J., "The Effect of a Spike Protruding in Front of a Bluff: Body at Supersonic Speeds," Aeronautical Research Council, R. \& M. No. 3007, 1957

[34] Stalder, J. R. and Nielson, H. V., "Heat Transfer from a Hemisphere Cylinder Equipped with Flow Separation Spikes," NACA TN 3287, Sept. 1954.

[35] Moeckel, W. E., " Flow Separation Ahead of a Blunt Axially Symmetric Body at Mach Numbers 1.76 to 2.10," NACA RM E51I25, 1951

[36] Mair, W. A. "Experiments on Separation of Boundary Layers on Probes in front of Blunt-Nosed Bodies in a Supersonic Air Stream," Philosophy Magazine, Ser.7, Vol.43, No. 243, July 1952, pp. 695-716

[37] Jones, J. J., "Flow Separation from Rods Ahead of Blunt Noses at Mach Number 2.7," NACA RM L52E05a, July, 1952

[38] Jones, J. J., "Experimental Drag Coefficients of Round Noses with Conical Windshields at Mach Number 2.72," NACA RM L55E10, June, 1955.

[39] Hermach, C. A., Kraus, K., and Reller, J. O., " Reduction in Temperature-Recovery Factor Associated with Pulsating Flows Generated by Spike-Nosed Cylinders at a Mach Number of 3.50," NACA RM A56L05, March, 1957.

[40] Chapman, D. R., Kuehn, D. M., and Larson, H. K., "Investigation of Separated Flows in Supersonic and Subsonic Streams with Emphasis on the Effect of Transition," NACA TR 1356, 1957

[41] Khlebnikov, V. S., "Distribution of Heat Flux on the Surface of a Sphere with a Forward Separation Zone," Fluid Dynamics, Vol. 21, No. 4, 1986, pp: 654- 658.

[42] Staylor, W. F., " Flow-Field Investigation for Large-Angle Cones with Short Spikes at a Mach Number of 9.6," NASA TN D-5754, 1970

[43] D’Humieres, G. and Stollery, J. L., "Drag Reduction on a Spiked Body at Hypersonic Speeds," The aeronautical Journal, Vol. 114, No. 1152, 2010, pp. 113-119

[44] Milicev, S. S., Pavlovic, M. D., Ristic, S., Vitic, A., "On the Influence of Spike Shape at Supersonic Flow past Blunt Bodies," Mechanics, Automatic Control and Robotics, Vol. 3, No. 12, 2002, pp. 371- 382.

[45] Kalimuthu, R., Mehta, R. C., and Rathakrishnan, E., "Drag Reduction for Spike Attached to Blunt-Nosed Body at Mach 6," Journal of Spacecraft and Rockets, Vol. 47, No. 1, 2010, pp. 219- 222.

[46] Myshenkov, V. N., "Numerical Investigation of Separated Flow in front of a Spiked Cylinder," Fluid Dynamics, Vol. 16, No., 6, 1981, pp. 938- 942

[47] Paskonov, V. M. and Cheranova, N. A., "Numerical Investigation of Laminar Separation in the Case of Supersonic Flow of Viscous Gas past Spiked Bodies," Fluid Dynamics, Vol. 19, No. 2, 1984, pp. 281- 285. 
[48] Karlovskii, V. N. and Sakharov, V. I., "Numerical Investigation of Supersonic Flow past Blunt Bodies with Protruding Spikes," Fluid Dynamics, Vol. 21, No., 3, 1986, pp. 437- 445

[49] Mikhail, A. G., "Spike-Nosed Projectiles with Vortex Rings: Steady and Nonsteady Flow Simulations," Journal of Spacecraft and Rockets, Vol. 33, No. 1, 1996, pp. 8 14.

[50] Hur, K. H., Kirn, S .T. and Lee, D. H., " Numerical Analysis on Supersonic, Viscous Flowfield around a Spike-Nosed Projectile with Fins," AIAA paper 96-3449-CP, 1996

[51] Yamauchi, M., Fujii, K., and Higashino, F., "Numerical Investigation of Supersonic Flows Around a Spiked Blunt Body," Journal of Spacecraft and Rockets, Vol. 32, No. 1, 1995, pp. $32-42$

[52] Mehta, R. C., "Numerical Analysis of Pressure Oscillations over Axisymmetric Spiked Blunt Bodies at Mach 6.8," Shock Waves, Vol. 11, No. 3, 2002, pp. 431-440

[53] Asif, M., Zahir, S., Kamran, N., and Khan, M., " Computational Investigations Aerodynamic Forces at Supersonic/ Hypersonic Flow past a Blunt Body with various Forward Facing Spikes," AIAA paper 2004-5189, 2004

[54] Srinivasan, G. R., and Chamberlain, R. R., "Drag Reduction of Spiked Missile by Heat Addition," AIAA paper 2004-4714, 2004

[55] Reding, J. P. and Jecmen, D. M., "Effects of External Burning on Spike-Induced Separated Flow," Journal of Spacecraft and Rockets, Vol. 20, No. 5, 1983, pp. 452 453

[56] Jagadeesh, G., Viren, M., Reddy, K. P. J., Hashimoto, T., Sun, M., and Takayama, K., "Hypersonic Buzz Phenomenon in the Spiked Blunt Cones," AIAA paper 2003-284, 2003

[57] Srulijes, J., Gnemmi, P., Seiler, F. and Runne, K., "Shock Tunnel High Speed Photography and CFD Calculations on Spike-Tipped Bodies," French-German Research Inst. of Saint-Louis, ISL Rept. PU 649/2002, Saint-Louis Codex, France, Sept.-Oct. 2002

[58] Kulkarni V., Kulkarni P. S., and Reddy K. P. J., "Drag Reduction by a Forward Facing Aerospike for a Large Angle Blunt Cone in High Enthalpy Flows," Proceedings of the 26th International Symposium on Shock Waves, July, 2007, pp. 566- 570.

[59] Roveda, R., "Benchmark CFD Study of Spiked Blunt Body Configurations," AIAA paper 2009-367, 2009

[60] Kabelitz, H., "Zur Stabilität Geschlossener Greznschichtablösegebeite an Konischen Drehkörpern bei Hyperschallströmung," DLR, FB 71-77, Germany, 1971

[61] Antonov, A. N., and Grestov, V. K., "Unsteady Separated Supersonic Flow over Pointed and Spiked Bodies," Fluid Dynamics, Vol. 9, No. 4,1974.pp. 578- 582.

[62] Antonov, A. N. and Gretsov, V. K., "Experimental Investigation of the Characteristics of Unsteady-State Breakaway Zones Arising in a Supersonic Flow at a Needle with a Screen," Fluid Dynamics, Volume 12, Number 4 / July, 1977, pp. 567- 572

[63] Antonov, A. N. and Shalaev, S. P., "Nonstationary Separation on Spiked Bodies," Fluid Dynamics, Vol. 14, No. 1, 1979, pp. 71- 76.

[64] Antonov, A. N., Gretsov, V. K. and Shalaev, S. P., "Nonsteady Supersonic Flow over Spiked Bodies," Fluid Dynamics, Volume 11, Number 5 / September, 1976, pp. 746751

[65] Kenworthy, M., "A Study of Unsteady Axisymmetric Separation in High Speed Flows," Ph.D. Dissertation, Dept. of Aerospace and Ocean Engineering, Virginia Polytechnic Inst. And State Univ., Blacksburg, VA., 1978

[66] Panaras , A. G., "Pulsating Flows about Symmetric Concave Bodies," AIAA Journal, Vol. 19, No. 6, 1981, pp. 804-806

[67] Panaras, A. G., "High Speed Unsteady Separation about Concave Bodies- A Physical Expanation," Von Karaman Institute, Technical Note 123, 1977. 
[68] Zapryagaev, V. I. and Mironov S. G., "Features of Separated Supersonic Flow Pulsations Ahead of a Spike-Tipped Cylinder," Journal of Applied Mechanics and Technical Physics, Vol. 32, No. 6, 1991, pp. 913-919

[69] Zapryagaev, V. I. and Kavun, I. N., "Experimental Study of the Reverse Flow in the Forward Separation Region in a Pulsating Flow around a Spiked Body," Journal of App. Mech. And Tech. Physics., Vol. 48, No. 4, 2007, pp. 492-500.

[70] Shang, J. S., Hankey, W. L., and Smith, R. E., "Flow Oscillations on Spiked Tipped Bodies," AI AA paper 80-0062, 1980

[71] Shang, J. S. and Hankey, W. L., "Flow Oscillations on Spiked Tipped Bodies," AIAA Journal, Vol. 20, No. 1, 1982, pp. 25-26.

[72] Feszty, D., Badcock, K. and Richards, B., "Driving Mechanisms of High-Speed Unsteady Spiked Body Flows, Part1: Pulsation Mode," AIAA Journal, Vol. 42, No. 1, 2004, pp. 95- 106

[73] Feszty, D., Badcock, K. and Richards, B., "Driving Mechanisms of High-Speed Unsteady Spiked Body Flows, Part2: Oscillation Mode," AIAA Journal, Vol. 42, No. 1, 2004, pp. 107- 113

[74] Feszty, D., Badcock, K., Richards, B., and Woodgate, M., "Numerical Simulation of a Pulsating Flow Arising over an Axisymmetric Spiked Blunt Body at Mach 2.21 and Mach 6.00," Shock Waves, Vol. 10, No. 5, 2000, pp. 323-331

[75] Feszty, D., Badcock, K. and Richards, B., "Numerical Simulation of the Hysteresis Phenomenon in High-Speed Spiked Body Flows," AIAA paper 2000-0141, 2000.

[76] Thurman, W. E., "A Flow-Separation Spike for Hypersonic Control of a Hemisphere Cylinder," AIAA Journal, Vol. 2, No. 1, 1964, pp. 159- 161

[77] Schulein, E., "Wave drag reduction concept for blunt bodies at high angles of attack," Shock waves 1, Springer Berlin Heidelberg, 2009, pp. 1315-1320

[78] Khlebnikov, V. S., "Effect of Unsteady Disturbances on the Flow in a Forward Separation Zone," Fluid Dynamics, Vol. 27, No. 2, 1992, pp. 294- 297.

[79] Khlebnikov, V. S., "The Influence of Unsteady Perturbations on the Flow in a Forward Separation Region Upstream of a Cone," Fluid Dynamics, Vol. 31, No. 2, 1996, pp: 274- 283.

[80] Khlebnikov, V. S., "Effect of Periodic Disturbances on the Flow in a Nonsymmetric Separation Zone ahead of a Blunt Body," Fluid Dynamics, Vol. 31, No. 5, 1996, pp. $731-738$. 
Appendix A: Summary of Previous Studies on Spiked Bodies Aerothermodynamics

\begin{tabular}{|c|c|c|c|c|c|c|c|c|c|c|c|c|c|}
\hline \multirow[b]{2}{*}{ Ref. } & \multirow[b]{2}{*}{$\begin{array}{l}\text { Type of } \\
\text { study }\end{array}$} & \multicolumn{2}{|c|}{ Conditions } & \multicolumn{3}{|c|}{ Geometry } & \multicolumn{6}{|c|}{ Focus of study } & \multirow[b]{2}{*}{ Special features } \\
\hline & & $\mathbf{M}$ & Alpha & Forebody & $\begin{array}{l}\text { spike tip/ } \\
\text { aerodisk }\end{array}$ & L/D & $\mathbf{S}$ & $\mathbf{D}$ & $\mathbf{L}$ & $\mathbf{P}$ & A 1 & $\mathbf{U}$ & \\
\hline 13 & $\mathbf{F}$ & $0.95: 1.37$ & 0 & $\mathrm{BO} / \mathrm{SO}$ & $\mathbf{C A}$ & 1.5 & & $\Delta$ & & & & & First study ever \\
\hline 35 & $\mathbf{E}$ & 1.76: 1.93 & 0 & $\mathbf{H}$ & PT & $1: 12$ & & $\Delta$ & & & & & \\
\hline 36 & $\mathbf{E}$ & 1.96 & 0 & FC/H & PT & Up to 6 & $\Delta$ & $\Delta$ & & & 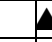 & $\mathbf{t}$ & First record of pulsation \\
\hline 37 & $\mathbf{E}$ & 2.72 & 0 & SK & PT & Up to 4.5 & $\Delta$ & & & & & & \\
\hline 28 & $\mathbf{F}$ & $0.7: 1.3$ & 0 & $\mathbf{H}$ & PT & Up to 2 & & $\Delta$ & & & & & The term "spike" introduced \\
\hline 34 & $\mathbf{E}$ & $0.12: 5.04$ & 0 & $\mathbf{H}$ & FT/ CA & $0.5: 2$ & & & & 4 & $\mathbf{\Delta}$ & & First aeroheating study \\
\hline 38 & $\mathbf{E}$ & 2.72 & 0 & H/BK & CA & Up to 2 & & A & & & & & $\begin{array}{c}\text { Impact of spike aerodisk } \\
\text { length }\end{array}$ \\
\hline 33 & $\mathbf{E}$ & $1.5: 1.8$ & 0 & FC & PT & Up to 4.7 & A & & & & 2 & $\mathbf{A}$ & $\begin{array}{l}\text { First record of hysteresis and } \\
\text { oscillation }\end{array}$ \\
\hline 39 & $\mathbf{E}$ & 3.5 & 0 & FC & PT & Up to 2 & & & & 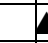 & $\Delta$ & $\mathbf{x}$ & \\
\hline 11 & $\mathbf{E}$ & 14 & 0 & FC/H & PT & Up to 8 & & $\Delta$ & & 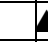 & $\Delta$ & $\underline{\underline{z}}$ & \\
\hline 23 & $\mathbf{E}$ & 6.8 & 0 & $\mathbf{H}$ & PT & Up to 4 & & $\Delta$ & & 4 & $\boldsymbol{\Delta}$ & & \\
\hline 9 & $\mathbf{E}$ & 6.8 & 0 & FC & PT & Up to 3 & $\Delta$ & & & & 4 & 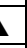 & Impact of shoulder roundness \\
\hline 22 & $\mathbf{E}$ & 10 & 0 & SK & PT & Up to 5 & A & & & & 4 & $\mathbf{\Lambda}$ & $\begin{array}{l}\text { Impact of cone angle, declare } \\
\text { flow patterns }\end{array}$ \\
\hline 8 & $\mathbf{E}$ & 19.4 & 0 & BO/H & PT & Up to 5 & & $\Delta$ & & 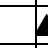 & $\boldsymbol{\Delta}$ & & \\
\hline 76 & $\mathbf{E}$ & 11.76 & $0: 7$ & $\mathbf{H}$ & PT & 4 & & A & & & & & $\begin{array}{l}\text { The spike is deflected w.r.t. } \\
\text { model axis }\end{array}$ \\
\hline 29 & $\mathbf{E}$ & 10.1 & $0: 25$ & FC/BK & PT & Up to 5 & & $\Delta$ & & & & & Very low Reynolds number \\
\hline 30 & $\mathbf{E}$ & 10 and 15 & 0 & H/FC/SK & PT & Up to 4 & $\Delta$ & & & 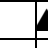 & $\Delta$ & 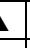 & Declare more flow patterns \\
\hline 26 & $\mathbf{E}$ & $3,4,6$ & 2,5 & BK & CA & $\begin{array}{l}0.055: \\
0.083\end{array}$ & A & & & & 4 & 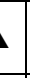 & Impact of very short spikes \\
\hline 42 & $\mathbf{E}$ & 9.6 & 0 & BK,SK & CA & Up to 0.13 & $\Delta$ & & & 4 & $\Delta$ & 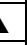 & \\
\hline 60 & $\mathbf{E}$ & & & NA & & & & & & & & & $\begin{array}{l}\text { New terms: "pulsation" and } \\
\text { "oscillation" }\end{array}$ \\
\hline 61 & $\mathbf{E}$ & 6 & 0 & FC & PT & Up to 3 & $A$ & A & & 4 & $\Delta$ & & $\begin{array}{c}\text { Range of spike length for } \\
\text { each flow modes }\end{array}$ \\
\hline 64 & $\mathbf{E}$ & 6 & 0 & FC & PT & Up to 3 & $\Delta$ & & & & 4 & 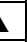 & Explain the pulsation mode \\
\hline 14 & $\mathbf{E}$ & Up to 3.5 & $>0$ & BO & BA & $\begin{array}{c}\text { Telescopin } \\
\mathrm{g}\end{array}$ & $\Delta$ & A & & & 4 & 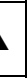 & $\begin{array}{l}\text { Aerodisk superiority, spike } \\
\text { bending }\end{array}$ \\
\hline 20 & $\mathbf{E}$ & Up to 4 & $0,4,8$ & BO & BA & 0.8 & $\Delta$ & & & & 4 & $\underline{\underline{E}}$ & \\
\hline 62 & $\mathbf{E}$ & $2: 6$ & 0 & SK & PT & Up to 5 & A & & & & 4 & 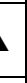 & $\begin{array}{c}\text { Amplitude and frequency of } \\
\text { unsteadiness }\end{array}$ \\
\hline 67 & $\mathbf{E}$ & - & 0 & FC & PT & - & $\Delta$ & & & & 1 & 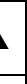 & $\begin{array}{l}\text { Explain the pulsation } \\
\text { (independent of [64]) }\end{array}$ \\
\hline 65 & $\mathbf{E}$ & & & NA & & & $\Delta$ & & & & 4 & $\underline{\underline{y}}$ & Explain the oscillation mode \\
\hline 63 & $\mathbf{E}$ & $2: 6$ & 0 & SK & PT & Up to 5 & $\Delta$ & & & & 4 & 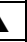 & \\
\hline 70 & NE & 3 & 0 & TK & RT & 0.75 & A & & & & 4 & 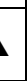 & $\begin{array}{l}\text { First numerical study of } \\
\text { pulsation }\end{array}$ \\
\hline 66 & $\mathbf{E}$ & - & 0 & FC & PT & - & $\Delta$ & & & & 4 & 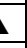 & \\
\hline 46 & $\mathbf{N}$ & $0.5: 3$ & 0 & FC & PT & Up to 3.25 & $A$ & A & & & & & $\begin{array}{l}\text { First comprehensive } \\
\text { numerical study }\end{array}$ \\
\hline 71 & NE & 3 & 0 & TK & RT & 0.75 & $\Delta$ & & & & 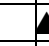 & $\underline{\mathbf{S}}$ & \\
\hline 55 & $\mathbf{E}$ & 2.2 & 0 & BO & FA & 1 and 1.875 & A & A & & & & & $\begin{array}{l}\text { Injection/ burning of gas jet } \\
\text { at aerodisk }\end{array}$ \\
\hline 47 & $\mathbf{N}$ & $2: 6$ & 0 & FC/SK & PT & Up to 1 & & $\Delta$ & & 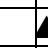 & $\boldsymbol{\Delta}$ & & Low Reynolds number \\
\hline 18 & $\mathbf{E}$ & 3 & 0 & TK & RT & 0.75 & $\Delta$ & & & & 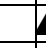 & 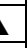 & Extensible spike \\
\hline 41 & $\mathbf{E}$ & 3 & 0 & $\mathbf{H}$ & CA/ PA & $0.283: 1.78$ & & & & 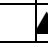 & $\boldsymbol{\Lambda}$ & & \\
\hline 48 & $\mathbf{N}$ & $3: 8$ & 0 & TK & RT & Up to 1 & $A$ & & & & & & \\
\hline 2 & $\mathbf{N E}$ & 2.5 & 0 & BK/H & BCA & $2: 9$ & $\Delta$ & $\Delta$ & & & & & \\
\hline 27 & $\mathrm{NE}$ & 1.72 & 0 & FC & FT & $\begin{array}{c}1.08 \text { and } \\
1.47\end{array}$ & $\Delta$ & $A$ & & & & & \\
\hline 68 & $\mathbf{E}$ & 2 and 3 & 0 & FC & PT & Up to 1.5 & $A$ & & & & 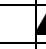 & 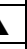 & \\
\hline 78 & $\mathbf{E}$ & 3 & 0,10 & FC/SK/H & WA & Up to 1.68 & & $A$ & & & $\boldsymbol{\Delta}$ & & $\begin{array}{l}\text { Introduce the "rotating } \\
\text { aerodisk" }\end{array}$ \\
\hline 3 & NE & 4 & 0 & H/HC & FT & \begin{tabular}{|c|}
0.875 and \\
1.3 \\
\end{tabular} & & 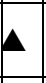 & & & $\boldsymbol{\Delta}$ & & \\
\hline 6 & $\mathbf{E}$ & 6.06 & $0: 40$ & HC & FA & & & A & & 1 & $\boldsymbol{\Delta}$ & & \\
\hline
\end{tabular}


Appendix A (continued): Summary of Previous Studies on Spiked Bodies Aerothermodynamics

\begin{tabular}{|c|c|c|c|c|c|c|c|c|c|c|}
\hline Ref. & $\begin{array}{l}\text { Type of } \\
\text { study }\end{array}$ & \multicolumn{2}{|c|}{ Conditions } & \multicolumn{3}{|c|}{ Geometry } & \multicolumn{3}{|c|}{ Focus of study } & \multirow[t]{2}{*}{ Special features } \\
\hline 51 & NE, V[23] & $\begin{array}{c}2.01,4.15 \\
6.8\end{array}$ & 0,10 & $\mathbf{H}$ & PT & $0.5,1$ and 2 & $2 \boldsymbol{A}$ & & 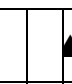 & \\
\hline 49 & NE & 1.72 & 0 & FC & FT & $\begin{array}{l}1.08 \text { and } \\
1.47\end{array}$ & $\mathbf{A}$ & & & \\
\hline 50 & NE & 3 & 0,2 & H/FC & FT & 1.42 & $\Delta$ & & & \\
\hline 79 & $\mathbf{E}$ & 3 & 0,10 & $\begin{array}{c}\text { FC/SK/ } \\
\text { H }\end{array}$ & WA & Up to 1.68 & $\mathbf{A}$ & & A & Rotating aerodisk \\
\hline 80 & $\mathbf{E}$ & 3 & 0,10 & \begin{tabular}{|c|} 
FC/SK/ \\
H
\end{tabular} & WA & Up to 1.68 & $\mathbf{A}$ & & $\mathbf{A}$ & Rotating aerodisk \\
\hline 5 & NV[23,51] & \multicolumn{5}{|c|}{ Numerical reproduction of $[23,51]$} & $\mathbf{A} \mathbf{A}$ & & $\Delta$ & \\
\hline 7 & NV[23,51] & \multicolumn{5}{|c|}{ Numerical reproduction of $[23,51]$} & $\Delta$ & & A & \\
\hline 74 & NV[65] & 6 & 0 & FC & PT & 1 & $\mathbf{A}$ & & 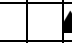 & 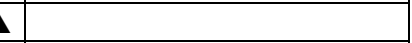 \\
\hline 75 & NV[65] & 2.21 & 0 & FC & PT & $1.25: 2.4$ & $\mathbf{A}$ & & + & $\begin{array}{c}\text { Fine numerical study of } \\
\text { hysteresis }\end{array}$ \\
\hline 21 & $\mathbf{E}$ & 7 & $0: 8$ & $\mathbf{H}$ & $\begin{array}{c}\text { FT/ RT/ HA/ } \\
\text { FA }\end{array}$ & 0.5 and 1 & $\mathbf{A}$ & & $\mathbf{A}$ & $\begin{array}{c}\text { Drag decomposition, pitching } \\
\text { moment }\end{array}$ \\
\hline 25 & $\mathbf{E}$ & 1.89 & $-4: 10$ & $\mathbf{H}$ & FT /RT/ PT & 1 & $\mathbf{A}$ & $\mathbf{A}$ & & Impact of spike tip shape \\
\hline 32 & $\mathbf{E}$ & $0.92,1.62$ & 0 & $\mathbf{H}$ & CA & 0.773 & $\mathbf{A}$ & & & Aerodisk on struts, no stem \\
\hline 44 & $\mathbf{E}$ & 1.89 & $-4: 10$ & $\mathbf{H}$ & FT /RT/ PT & 1 & A & $\mathbf{A}$ & & \\
\hline 52 & NV[23] & \multicolumn{5}{|c|}{ Numerical reproduction of [23] } & $\mathbf{A}$ & & 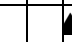 & 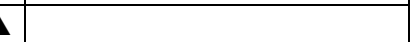 \\
\hline 1 & EN & 5.75 & $0: 12$ & BK & FA & 1 & $\mathbf{A}$ & & & \\
\hline 57 & EN & 4.5 & $0: 24$ & $\mathbf{H}$ & FA/ HA/ BCA & 1 & $\Delta \mathbf{A}$ & & & \\
\hline 56 & EN & 5.75 & 0 & BK & FA & 1 & $\mathbf{A}$ & & 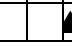 & 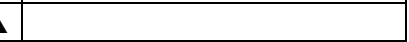 \\
\hline 10 & EN & 5.75 & $0: 12$ & BK & FT/ HA/ FA & Up to 1 & A & & A & \\
\hline 4 & EN & 4.5 & $0: 24$ & $\mathbf{H}$ & FA/ HA/ BCA & 1 & $\mathbf{A} \mathbf{A}$ & & & \\
\hline 53 & NV[23,25] & $4: 8$ & $0: 12$ & $\mathbf{H}$ & PT & $0.5,1$ & $\mathbf{A} \mathbf{A}$ & $\mathbf{\Delta} \mathbf{A}$ & $\Delta$ & \\
\hline 54 & EN & 2.2 & 0 & BO & FA & 1 and 1.875 & $5 \mathbf{A}$ & & & \\
\hline 72 & NV[65] & 2.21 & 0 & FC & PT & 1 & $\boldsymbol{A}$ & & 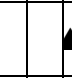 & $\begin{array}{c}\text { Fine numerical study of } \\
\text { pulsation }\end{array}$ \\
\hline 73 & NV[65] & 6 & 0 & FC & PT & 2 & A & & 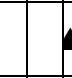 & $\begin{array}{c}\text { Fine numerical study of } \\
\text { oscillation }\end{array}$ \\
\hline 24 & NV $[4,6]$ & 6.06 & $0: 40$ & $\mathrm{HC}$ & FA & 3 & $\mathbf{A}$ & & A & \\
\hline 58 & EN & 8 & 0 & BK & FA & 1 & $\mathbf{A}$ & & & \\
\hline \begin{tabular}{|l|}
69 \\
\end{tabular} & $\mathbf{E}$ & 6.08 & 0 & FC & PT & Up to 1.5 & $\mathbf{A}$ & & $t$ & \\
\hline \begin{tabular}{|l|}
16 \\
\end{tabular} & $\mathbf{E}$ & 6 & $0: 8$ & $\mathbf{H}$ & HA/FA & 1.5 and 2 & $\mathbf{A}$ & $\Delta \mathbf{A}$ & & \\
\hline 15 & NV[23] & $5,7,10$ & 0 & BK & RT/ HA & $1: 4$ & $\Delta \mathbf{A}$ & & $\Delta$ & \\
\hline \begin{tabular}{|l|}
77 \\
\end{tabular} & $\mathbf{E}$ & $2,3,5$ & $0: 30$ & $\mathbf{H}$ & PT & - & $\mathbf{A}$ & & $A$ & "Pivoting spike" concept \\
\hline 31 & $\mathbf{E}$ & 6 & 0,4 & $\mathbf{H}$ & RT & 1 & $A$ & & & $\begin{array}{c}\text { Injection/ burning of gas jet at } \\
\text { aerodisk }\end{array}$ \\
\hline 12 & NV[16] & \multicolumn{5}{|c|}{ Numerical reproduction of [16] } & & & & \\
\hline 59 & NV $[4,6,24]$ & \multicolumn{5}{|c|}{ Numerical reproduction of $[4,6,24]$} & $\boldsymbol{A}$ & & & $\begin{array}{l}\text { Comparing the commercial } \\
\text { CFD codes }\end{array}$ \\
\hline 17 & \begin{tabular}{|c|}
$\mathrm{NV}[18,23,65$ \\
$, 67]$ \\
\end{tabular} & \multicolumn{5}{|c|}{ Numerical reproduction of $[18,23,65,67]$} & $\boldsymbol{\Delta}$ & & & \\
\hline \begin{tabular}{|l|}
43 \\
\end{tabular} & $\mathbf{E}$ & 8.2 & 0 & H/SK & PT & Up to 2.125 & $5 \mathbf{A} \mathbf{A}$ & & & \\
\hline
\end{tabular}

BA blunt aerodisk,

BK blunt cone,

BO blunt ogive

CA conical aerodisk

E experimental study,

EN experimental study with numerical validation,

F firing test,

FA flat aerodisk,

FC flat-faced cylinder,

FT flat tip

H Hemisphere

HA hemispherical aerodisk,
HC hemisphere-capped cylinder

N numerical study with no experimental validation

NA The reference was not available during the study

NE numerical study, validation with own experimental results

NV[10] numerical study, validation with experiment of [10]

PA pyramid aerodisk,

PT pointed tip

RT rounded tip,

SK sharp cone,

SO sharp ogive

TK truncated cone

WA wedge aer odisk 